\section{Resolution of post-liver transplant anastomotic biliary stricture with successful placement of a self-expanding metallic stent in a child}
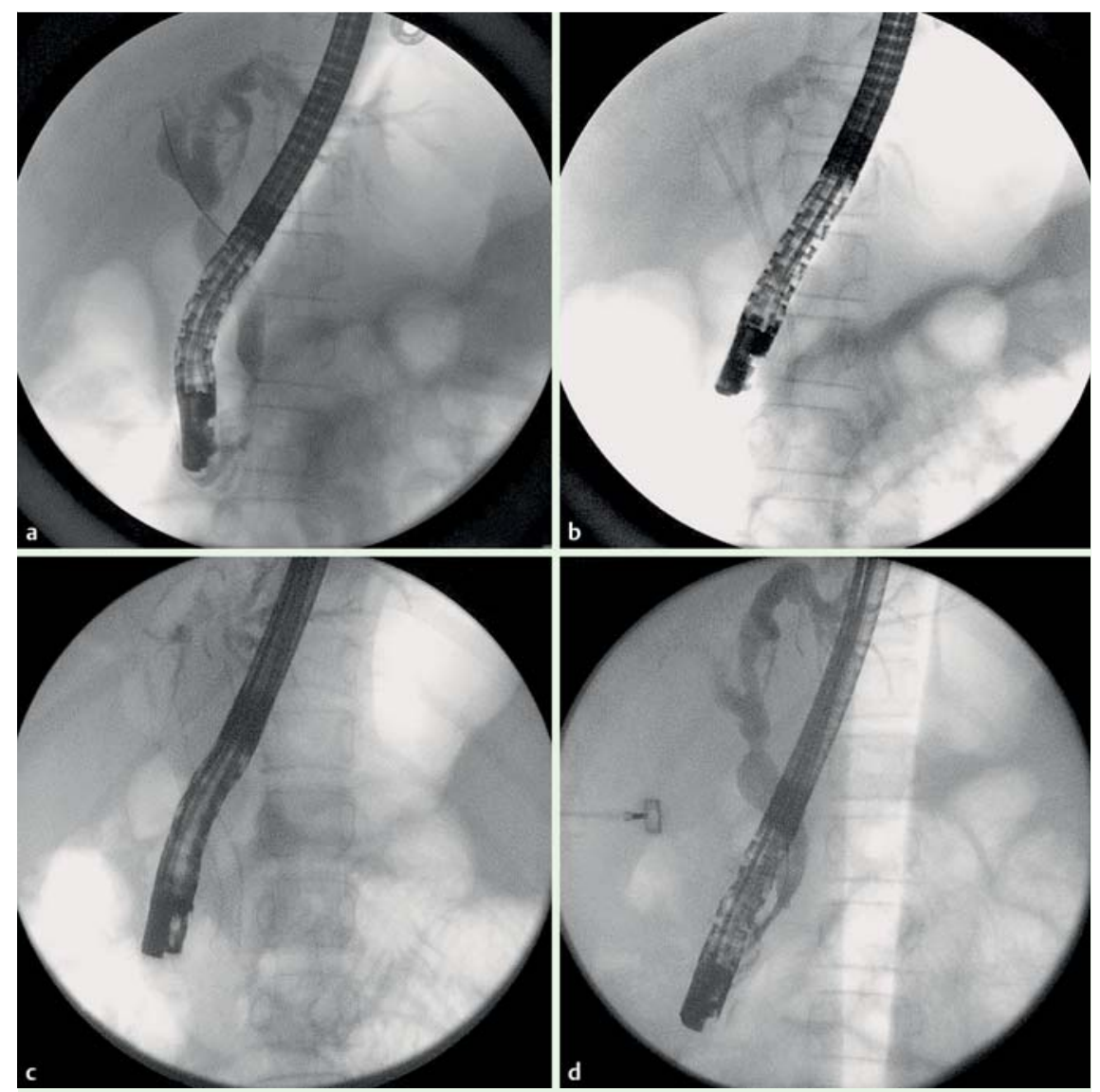

Fig. 1 Fluoroscopic images from a 9-year-old girl with anastomotic biliary stricture following liver transplant. a Tight anastomotic biliary stricture with proximal intrahepatic ductal dilatation. b Two plastic biliary stents with adequate decompression. c Self-expanding metal stent in the bile duct with pneumobilia. $\mathbf{d}$ Marked resolution of the stricture following removal of the metal stent.

A 9-year-old girl who had received an orthotopic liver transplant for cryptogenic cirrhosis at the age of 5 years was admitted for the evaluation of elevated transaminases. Transabdominal ultrasound demonstrated intrahepatic biliary dilatation. Liver biopsy ruled out organ rejection, and endoscopic retrograde cholangiopancreatography (ERCP) confirmed the presence of a focal anastomotic stricture ( $\bullet$ Fig. 1 a).

The placement of two 7-Fr plastic biliary stents $($ Fig. $\mathbf{1 b}$ ) resulted in a decrease in her transaminase levels. Follow-up procedures with additional balloon dilatation and the placement of multiple 10 -Fr plas- tic stents normalized the liver enzyme levels, with a corresponding improvement in the radiological appearance of the stricture. However, the patient presented again 6 months later with a recurrence that responded to the placement of plastic biliary stents.

The parents preferred a minimally invasive approach before considering surgery. In order to provide lasting relief, the placement of a $60 \times 10-\mathrm{mm}$ metal stent (Wallstent; Boston Scientific, Natick, Massachusetts, USA) was undertaken safely ( $\bullet$ Fig. 1c). ERCP after 2 months revealed resolution of the anastomotic stricture ( Fig. 1d), and at clinical follow-up 6 months after stent removal, the patient had stable liver enzymes with no symptoms.

Overall, biliary complication rates following liver transplant vary from $12 \%$ to $50 \%$ [1], and anastomotic strictures occur in up to $10 \%$ of patients [2]. Whereas the utility of endotherapy in the adult population is well documented, data are limited for similar interventions in the cohort of pediatric patients with liver transplants [3]. The placement of a fully covered self-expanding metal stent is an emerging modality for the treatment of refractory biliary strictures following liver transplant [4]. However, there are no documented reports in pediatric patients with liver transplants. The persistent radial expansion force created by the metal stent appears to result in an adequate response of the ringlike focal anastomotic stricture and is the likely reason for the optimal response in our patient.

The placement of a fully covered selfexpanding metal stent is a viable and safe alternative to repeated stent insertion for carefully selected patients with biliary strictures following transplant and provides an alternative to the surgical management of strictures that are refractory to standard endoscopic therapy. However, the long-term effect of metal stent placement in pediatric patients is unknown.

\section{Endoscopy_UCTN_Code_TTT_1AR_2AZ}

\section{Competing interests: None}

\section{William P. Sonnier ${ }^{1}$, Devin Eckhoff ${ }^{2}$, Stephen Gray ${ }^{2}$, Jayapal Ramesh ${ }^{1}$}

${ }^{1}$ University of Alabama at Birmingham, Division of Gastroenterology-Hepatology, Birmingham, Alabama, USA

2 University of Alabama at Birmingham, Department of Liver Transplantation Surgery, Birmingham, Alabama, USA

\section{References}

1 Anderson $C D$, Turmelle YP, Darcy $M$ et al. Biliary strictures in pediatric liver transplant recipients - early diagnosis and treatment results in excellent graft outcomes. Pediatr Transplant 2010; 14: $358-363$

2 Karakayali F, Kirnap M, Akdur A et al. Biliary complications after pediatric liver transplantation. Transplant Proc 2013; 45: 3524-3527 
3 Dechene A, Kodde C, Kathemann S et al. Endoscopic treatment of pediatric post-transplant biliary complications is safe and effective. Dig Endosc 2015; 27: 505-511

4 Cerecedo-Rodriguez J, Phillips M, FigueroaBarojas $P$ et al. Self expandable metal stents for anastomotic stricture following liver transplant. Dig Dis Sci 2013; 58: 2661 - 2666
Bibliography

Dol http://dx.doi.org/

10.1055/s-0034-1392659

Endoscopy 2015; 47: E444-E445

(c) Georg Thieme Verlag KG

Stuttgart · New York

ISSN 0013-726X

\section{Corresponding author}

Jayapal Ramesh, MD, FRCP (UK), FASGE

Basil Hirschowitz Endoscopic Center of Excellence Division of Gastroenterology-Hepatology

University of Alabama at Birmingham

BDB 389

1808 7th Avenue South

Birmingham, Alabama 35294

USA

Phone: +1-205-996-4059

Fax: +1-205-975-6381

j1ramesh@gmail.com 